\title{
Effects of word frequency and age of acquisition on short-term memory span
}

\author{
STEVEN ROODENRYS, CHARLES HULME, JANICE ALBAN, and ANDREW W. ELLIS \\ University of York, York, England \\ and \\ GORDON D. A. BROWN \\ University of Wales, Bangor, Wales
}

\begin{abstract}
The experiments reported examine the effects of two highly related variables, word frequency and age of acquisition, on short-term memory span. Short-term memory span and speech rate were measured for sets of words which independently manipulated frequency and age of acquisition. It was found that frequency had a considerable effect on short-term memory span, which was not mediated by speech rate differences-although frequency did affect speech rate in one experiment. For age of acquisition, this situation was reversed; there was a small but significant effect of age of acquisition on speech rate, but no effect on memory span. This occurred despite results confirming that the stimuli used in the experiments produce an effect of age of acquisition on word naming. The results are discussed in terms of a two-component view of performance on short-term memory tasks.
\end{abstract}

In recent years, there has been intense interest in the effects of the age at which words are acquired on cognitive processes in adults. Age of acquisition has been shown to have effects on a variety of cognitive processes such as word and picture naming (see, e.g., Gilhooly \& Logie, 1981a, 1981b; Lachmann, Shaffer, \& Hennrikus, 1974; Morrison, Ellis, \& Quinlan, 1992). However, age of acquisition is highly correlated with word frequency, which also appears to have pervasive effects on cognitive processes. A major question, therefore, is to separate the effects of these two variables in order to understand how they exert their influences. The experiments reported in this paper aim to clarify whether these two variables affect short-term memory span, and if so, in what way.

It is known that verbal short-term memory tasks depend critically on phonological or articulatory coding (see Baddeley, 1986, and Penney, 1989, for reviews). Trace decay models of short-term memory assume that items are represented by traces that decay within a fixed period of time unless they can be refreshed by rehearsal, a process considered similar to the subvocal articulation of the items (Baddeley \& Hitch, 1974; Schweickert \& Boruff, 1986). One simple model of this type is embodied in the notion of an articulatory loop developed by Baddeley and his colleagues (e.g., Baddeley \& Hitch, 1974; Baddeley, Lewis, \& Vallar, 1984). The idea of an articulatory loop provides an explanation of a wide range

This research was supported by Grant R000 232576 from the Economic and Social Research Council of the United Kingdom to the second and fifth authors. Correspondence concerning this paper, including requests for reprints, should be sent to C. Hulme, Department of Psychology, University of York, York, YO1 5DD England. of data on short-term memory. In particular, the word length effect (Baddeley, Thomson, \& Buchanan, 1975), the finding that subjects can recall more short than long words in correct order, can be explained in terms of long words being spoken, and so rehearsed, more slowly than short words. The fact that articulatory suppression (repeating aloud an irrelevant word) reduces short-term memory span (Murray, 1968) is considered to occur because it blocks rehearsal so that items decay from the store because they cannot be refreshed.

A number of studies, however, have shown an effect of word frequency on short-term memory tasks, and this is difficult to explain in terms of trace decay models. Watkins (1977) found that memory span scores were higher when the first half of the list comprised highfrequency words and the second half low-frequency words than when this arrangement was reversed. He argued that the greater effect of frequency in the initial part of the list supported the notion that items early in the sequence were recalled from long-term memory, whereas later items were retrieved from short-term memory and consequently were not affected by word frequency.

Wright (1979), however, showed that low-frequency words took longer to articulate than high-frequency words, even when they were equated for the number of letters. He went on to demonstrate how this difference in spoken duration could explain the pattern in Watkins's (1977) data through the longer duration of lowfrequency words' allowing either greater decay or fewer rehearsals before recall. These explanations, therefore, are compatible with frequency having an effect on how quickly words can be rehearsed in the articulatory loop and require no direct contribution from long-term mem- 
ory to explain the frequency effect on short-term memory span.

However, Tehan and Humphreys (1988) measured how long it took subjects to read lists of words aloud. They found that high-frequency words were read more quickly than low-frequency words, even when they were equated for spoken duration. Gregg, Freedman, and Smith (1989) reported the same finding when the measure of rehearsal speed was the time taken to repeat triplets of words 10 times.

Both Tehan and Humphreys (1988) and Gregg et al. (1989) found differences in rehearsal rate for high- and low-frequency words and a corresponding difference in short-term memory span. However, they also found that the difference in memory span for high- and lowfrequency words did not disappear under articulatory suppression. This suggests that the effect of frequency on short-term memory span is not due to the operation of the articulatory loop, since suppression is presumed to prevent its operation.

More recently, Roodenrys, Hulme, Schweickert, and Brown (1994), using a different methodology, have also shown that memory span is influenced by word frequency independently of any effect of frequency on articulation. When memory span scores are adjusted to partial out any effect of speech rate between high- and low-frequency words, memory span remains higher for high-frequency words. They argued that retrieval of partially decayed traces from a short-term phonological store is facilitated by the availability of information about the phonological form of words stored in longterm memory. This lexical information is automatically retrieved and used to perform pattern completion on the decayed memory traces. This explanation is consistent with findings that memory span is greater for words than for nonwords (Hulme, Maughan, \& Brown, 1991). However, none of the experiments examining the effects of word frequency on short-term memory have controlled for the effects of age of acquisition. It is possible, therefore, that the effects obtained might reflect the effects of age of acquisition rather than frequency per se.

It has in fact been suggested that many apparent effects of word frequency on cognitive processes are due to age of acquisition rather than frequency. A review of the literature by Gilhooly and Watson (1981) suggests that age of acquisition effects are most marked in word production rather than word recognition tasks. In particular, a significant effect of age of acquisition has been observed in picture naming, category instance naming, word naming, anagram solving, and word completion.

Since short-term memory span appears to be largely determined by speech-related factors and age of acquisition appears to influence some speech-related processes, it seems likely that age of acquisition will affect short-term memory span. Until now, we have attributed the frequency effect on memory span that has not been mediated by speech rate to processes involved in accessing long-term memory representations of the phonologi- cal form of words. In particular, we have suggested that these processes are very similar to those involved in speech perception and production. However, given the high correlation between frequency and age of acquisition, it is possible that the effect that we have observed is due to age of acquisition rather than frequency, because age of acquisition was uncontrolled in these experiments. It is clearly important to establish whether frequency, age of acquisition, or both have an effect on short-term memory span. The first experiment was designed to clarify this issue.

\section{EXPERIMENT 1}

The first experiment was designed to examine the effects of frequency and age of acquisition on memory span independently. We selected two sets of words matched on word frequency and concreteness but differing in age of acquisition. We also selected two sets of words matched on age of acquisition and concreteness but differing in frequency. In addition to memory span, speech rate was also assessed for the different word pools in order to determine whether any effects observed on memory span could be attributed to differences in rehearsal rate.

\section{Method}

Subjects. The subjects were 24 undergraduate students at the University of York.

Materials. Two sets of eight words were selected. They were matched for length, number of phonemes, and age of acquisition, according to the norms of Gilhooly and Logie (1980), but they varied in frequency. The high-frequency set comprised words with a spoken frequency of 80 or more according to the norms of Brown (1984); the low-frequency set comprised words with a frequency of 10 or less.

Two sets of eight words matched on length and frequency but varying in age of acquisition, according to the norms of Gilhooly and Logie (1980), were also selected. The high age of acquisition set comprised words with a rating of 4.36 or higher; the low age of acquisition set comprised words with a rating of 3.39 or less. A rating of 3 indicates that the word is learned at 5 or 6 years of age; a rating of 4 indicates that the word is learned at 7 or 8 years of age. The sets were also matched for rated concreteness (Quinlan, 1992), and an attempt was made to avoid phonological or semantic similarities within the lists. The words, with their mean frequencies, age of acquisition, and concreteness ratings, are given in the Appendix.

Procedure. The experiment was conducted in a single session of approximately $35 \mathrm{~min}$. All the tasks in the experiment were controlled by a Macintosh SE/30; an external amplified speaker was used to present the previously recorded and digitized items, which were spoken in a female voice (see Cox, Hulme, \& Brown, 1992). Each subject completed a memory span procedure and speech rate measurement for each of the four conditions. The order of testing of the four conditions was counterbalanced across subjects.

In each condition, the subjects were initially presented with each word individually and were asked to repeat the item to check the item's audibility. To measure memory span, the subjects were presented with lists of words drawn randomly without replacement from the pool of eight items, at a rate of one item per second. The subjects were presented with four lists of items at each sequence length, beginning with three items. All subjects successfully re- 
called all the initial lists in all conditions. The length of the lists was increased by one item each time until the subject made errors on 3 or 4 of the lists at a given length. Memory span was calculated as the list length to which the subject had maintained errorfree performance, plus one quarter of a point for each subsequent list recalled correctly.

Following the memory span tasks, the subjects' speech rates were measured. For each condition, the subjects were presented with the eight items from that condition one at a time. The subjects were instructed to repeat each word 10 times as quickly as possible, and the time taken to do this was recorded. The mean of these eight times was then transformed to items articulated per second.

\section{Results}

The mean memory spans and speech rates for each set of words are shown in Table 1 . The data show a highly significant effect of frequency on memory span $[t(23)=$ $3.939, p<.001$, two-tailed], but no effect on speech rate $[t(23)=0.226, \mathrm{n} . \mathrm{s}$. $]$. For age of acquisition, the pattern is reversed, with a small but highly significant effect on speech rate $[t(23)=4.719, p<.001$, two-tailed], but no significant effect on memory $\operatorname{span}[t(23)=1.032$, n.s. $]$.

\section{Discussion}

The results of this experiment show clearly that when age of acquisition and item length are controlled, a strong effect of frequency on short-term memory span is observed. At the same time, it is apparent that when frequency and item length remain constant, there is no significant effect of age of acquisition on span. There is a small, highly significant effect of age of acquisition on speech rate, but this is not large enough to produce a reliable effect on memory span.

The size of the speech rate difference on our high and low age of acquisition words can be related to the size of the difference in memory span expected, given the relationship between speech rate and memory span. In our other studies relating memory span to speech rate for words of different frequencies, we have also manipulated word length (Roodenrys et al., 1994). These studies have employed procedures identical to that in the present experiment. The slope of the regression function relating memory span to speech rate in words per second in these studies varied between .67 and .75 . On the basis of these functions, the speech rate difference between high and low age of acquisition words in this experiment of 0.19 words per second should result in a span difference of .13 or .14; this fits perfectly with the observed difference of .14 items in memory span between our high and low age of acquisition words.

Table 1

Mean Span Scores and Speech Rates (Words/Second) From Experiment 1

\begin{tabular}{|c|c|c|c|c|}
\hline & \multicolumn{2}{|c|}{ Frequency } & \multicolumn{2}{|c|}{$\begin{array}{c}\text { Age of } \\
\text { Acquisition }\end{array}$} \\
\hline & Low & $\overline{\text { High }}$ & Low & High \\
\hline Memory span & 5.33 & 5.86 & 5.22 & 5.08 \\
\hline Speech rate & 3.44 & 3.43 & 2.80 & 2.61 \\
\hline
\end{tabular}

Our data confirm our previous finding that frequency has an effect on short-term memory span that is not mediated by speech rate. In addition, for the first time, we have shown that the frequency effect on short-term memory span observed by ourselves and others (Gregg et al., 1989; Roodenrys et al., 1994; Tehan \& Humphreys, 1988) is not merely a consequence of the related variable, age of acquisition.

The finding that age of acquisition does not affect short-term memory span seems somewhat surprising, given the evidence, discussed above, that it affects performance in other tasks involving speech production, such as naming speed. Given the intimate link between short-term memory processes and speech production, we thought it likely that age of acquisition would affect short-term memory span. We will discuss the theoretical implications of these results following Experiment 2.

\section{EXPERIMENT 2}

The purpose of Experiment 2 was to confirm that the words used in Experiment 1 differing in age of acquisition do differ in naming speed. A number of studies have reported effects of age of acquisition on word naming speed when frequency and word length have been controlled (e.g., Brown \& Watson, 1987; Gilhooly \& Logie, 1981a, 1981b; Rubin, 1980). If we can show such an effect for the words used in Experiment 1, it will rule out the possible objection that our failure to find a difference in short-term memory span for these words arose from a weak or inappropriate manipulation of age of acquisition in that experiment.

\section{Method}

Subjects. The subjects were 15 undergraduate students at the University of York.

Materials. The four sets of eight words from Experiment 1 were used in this experiment along with an additional 50 filler words and 10 practice words. The filler words had approximately the same distributions on frequency and age of acquisition as the experimental words.

Procedure. The experiment was conducted in a single session of approximately $10 \mathrm{~min}$. A Macintosh computer was used to randomize and present the stimuli to the subjects. The subjects' responses were recorded on audio tape for later analysis.

The subjects were informed that they would see a number of words appearing on the screen in succession and that their task was to read each word aloud as quickly as possible. They were then presented with 92 trials. On the first 10 trials, practice items were presented, and the remaining trials were presentations of the 32 experimental words and 50 filler words. The words were presented in a different random order for each subject.

On each trial an asterisk appeared at the center of the screen for $1 \mathrm{sec}$. This was immediately replaced by a word for $1.5 \mathrm{sec}$ before the screen went blank. There was a 1 -sec interval between trials. When each item was presented, the computer generated a tone that was recorded on the channel of the audio tape opposite to the one used to record the subject's response. The tone was not audible to the subject.

For each trial, the interval between the presentation of the item and the beginning of the subject's response was measured by digitizing the tape recording of the trial using MacRecorder and ex- 
Table 2

Mean Naming Latency Responses (in Milliseconds) in Experiment 2

\begin{tabular}{lccccc} 
& \multicolumn{2}{c}{ Low } & & \multicolumn{2}{c}{ High } \\
\cline { 2 - 5 } & $M$ & $S D$ & & $M$ & $S D$ \\
\hline Age of acquisition & 439 & 56 & & 470 & 68 \\
Frequency & 464 & 62 & & 427 & 51 \\
\hline
\end{tabular}

amining the visual waveform. Response latencies were measured to the nearest millisecond.

\section{Results}

The mean response latencies for each of the four sets of words are shown in Table 2. These figures are based on the responses of all the subjects to all the target items, with the exception of two occasions when the subject coughed. The responses were analyzed across both subjects and items in paired $t$ tests. The results of the analysis by subjects showed significant effects of both frequency $[t(14)=4.04, p<.001$, one-tailed] and age of acquisition $[t(14)=5.33, p<.001$, one-tailed]. The analysis by items also showed significant effects of both frequency $[t(7)=1.90, p<.05$, one-tailed] and age of acquisition $[t(7)=2.46, p<.05$, one-tailed].

Because we were dealing with a very small sample of words, in comparing the conditions we used the stringent quasi $F$ ratio, which takes account simultaneously of variability across subjects and items (Clark, 1973). The analyses of the mean latencies shown in Table 3 revealed a significant effect of age of acquisition $\left[F^{\prime}(1,19)\right.$ $=4.53, p<.05]$, while the effect of frequency just failed to reach significance $\left[F^{\prime}(1,20)=3.95, p>.05\right]$.

\section{Discussion}

The results of Experiment 2 are important in confirming that the words used in Experiment 1 that differed in age of acquisition also differ in how quickly subjects can name them. Thus, the absence of an effect of age of acquisition on short-term memory span in Experiment 1 was not an artifact of an inappropriate selection of stimulus materials. In line with a number of other studies (e.g., Brown \& Watson, 1987; Gilhooly \& Logie, 1981a, 1981b; Rubin, 1980), we have shown that age of acquisition has effects on word naming that are not attributable to differences in word frequency. At the same time, the data show an effect of word frequency that is slightly weaker than the effect of age of acquisition. Although some studies have indicated that when age of acquisition is controlled

Table 3

Mean Naming Latency Responses (in Milliseconds) in Experiment 3

\begin{tabular}{|c|c|c|c|c|}
\hline & \multicolumn{2}{|c|}{ Low } & \multicolumn{2}{|c|}{ High } \\
\hline & $M$ & $S D$ & $M$ & $S D$ \\
\hline Age of acquisition & 424 & 40 & 445 & 42 \\
\hline Frequency & 443 & 46 & 435 & 44 \\
\hline
\end{tabular}

frequency does not have reliable effects on word naming speed (Brown \& Watson, 1987; Gilhooly \& Logie, $1981 \mathrm{a}, 1981 \mathrm{~b}$ ), this does not appear to have been true in this experiment.

\section{EXPERIMENT 3}

The purpose of Experiment 3 was to test the generality of the results of the first two experiments by using different, and slightly larger, sets of words. This experiment replicated both Experiments 1 and 2 within the same group of subjects.

\section{Method}

Subjects. The subjects were 28 first-year psychology students at the University of York who participated in compliance with a course requirement.

Materials. Two sets of 14 words matched pairwise on length (number of phonemes) and age of acquisition according to the norms of Gilhooly and Logie (1980) but varying in frequency were selected. The high-frequency set comprised words with a spoken frequency of 34 or more according to the norms of Brown (1984); the low-frequency set comprised words with a frequency of 9 or less. The sets were also matched on mean concreteness (Quinlan, 1992), number of letters, and number of syllables.

Two sets of 14 words matched pairwise on length (number of phonemes) and frequency but varying in age of acquisition according to the norms of Gilhooly and Logie (1980) were also selected. The high age of acquisition set comprised words with a rating of 4.06 or higher; the low age of acquisition set comprised words with a rating of 3.22 or less. The sets were also matched on concreteness, number of letters, and number of syllables. For all four sets, an attempt was made to avoid phonological or semantic similarities within the lists. The words, with their mean frequencies, age of acquisition, and concreteness ratings, are given in the Appendix.

Procedure. The experiment was conducted in a single session of approximately $50 \mathrm{~min}$. The procedure was as described for Experiments 1 and 2, except where noted, with the subjects in this experiment completing the naming task before the memory span tasks.

In the naming task, subjects were presented with 66 trials. On the first 10 trials, practice items were presented, and the remaining trials were presentations of the 56 experimental words. The words were presented in a different random order for each subject.

All aspects of the memory span and speech rate tasks were as described for Experiment 1, with the exception that the speech rate task measured the speed of repeating seven pairs of words 10 times, rather than each of the words individually.

\section{Results}

The mean response latencies for each of the four sets of words are shown in Table 3. These figures are based on the responses of all the subjects to all the target items, with the exception of nine occasions on which a subject made an error in pronunciation. The responses were analyzed by subjects and by items in paired $t$ tests. The results of the subjects analysis showed a significant effect of age of acquisition $[t(23)=5.75, p<.001$, two-tailed]; the effect of frequency just failed to reach significance $[t(23)=-2.24, p>.05$, two-tailed $]$. The items analysis also showed a significant effect of age of acquisition $[t(13)=2.60, p<.05$, two-tailed], but the effect of fre- 
Table 4

Mean Span Scores and Speech Rates (Words/Second) From Experiment 3

\begin{tabular}{|c|c|c|c|c|}
\hline & \multicolumn{2}{|c|}{ Frequency } & \multicolumn{2}{|c|}{$\begin{array}{c}\text { Age of } \\
\text { Acquisition }\end{array}$} \\
\hline & Low & High & Low & High \\
\hline Memory span & 5.35 & 5.73 & 5.20 & 5.24 \\
\hline Speech rate & 3.26 & 3.38 & 3.20 & 3.13 \\
\hline
\end{tabular}

quency was not significant $[t(13)=-0.84, p>.1$, twotailed].

Once again, because we were dealing with a small sample of words, we used the stringent quasi $F$ ratio, which takes account simultaneously of variability across subjects and items (Clark, 1973). The analyses of the mean latencies shown in Table 3 revealed a significant effect of age of acquisition $\left[F^{\prime}(1,34)=4.15, p<.05\right]$, while the effect of frequency was not significant $\left[F^{\prime}(1,27)<1\right]$.

The mean memory spans and speech rates for each set of words are shown in Table 4. The data show a highly significant effect of frequency on memory span $[t(27)=$ $4.161, p<.001$, two-tailed $]$ and on speech rate $[t(27)=$ $2.514, p<.05]$. However, the effect of age of acquisition on memory span was not significant $[t(27)=-0.366$, n.s.], and the effect on speech rate just failed to reach significance $[t(27)=-1.907, p>.05$, two-tailed $]$.

Because word frequency showed an effect on speech rate in this experiment, we could not be certain that there was an effect on span above and beyond the effect one would expect to arise from the difference in speech rate. In order to determine that there was an effect of frequency on memory span that was not mediated by speech rate, the span scores were subjected to a one-way analysis of covariance with speech rate as the covariate. This analysis revealed a significant effect of frequency on memory span when the effect on speech rate was partialled out $[F(1,26)=11.45, p<.01]$.

\section{Discussion}

The results of this experiment replicated the important findings from Experiments 1 and 2. This experiment again provided clear evidence that there is an effect of frequency on short-term memory span that is not mediated by speech rate and is not due to the correlated variable age of acquisition.

The data from the naming task showing a clear effect of age of acquisition suggest strongly that the absence of an effect of age of acquisition on short-term memory span is not an artifact of the stimulus materials. These data differ from those of Experiment 2 slightly, in that they provide less evidence for an effect of frequency on word naming.

The finding of a significant effect of frequency on speech rate in Experiment 3 differs from the results of Experiment 1 . This difference is not entirely surprising, since studies of the spoken duration of words have shown that the effect of frequency is larger with longer words (Geffen \& Luszcz, 1983; Wright, 1979). The words used in Experiment 1 were all monosyllables, whereas the words in Experiment 3 included a number of longer words. A reasonable explanation, therefore, for the slight difference in results between Experiments 1 and 3 is that differences in speech rate between high- and low-frequency words are more marked for longer words.

\section{GENERAL DISCUSSION}

Taken together, the results of our experiments reveal an interesting dissociation between the effects of frequency and age of acquisition. Word frequency had clear effects on short-term memory span that are not attributable to age of acquisition and are not mediated by differences in speech rate. On the other hand, frequency had only a weak effect, if any, on word naming speed. In contrast, age of acquisition was shown to affect word naming speed, and perhaps speech rate, but it did not have any significant effects on short-term memory span. This dissociation shows very clearly that age of acquisition and frequency have different effects on language processing mechanisms. Let us consider the effects we obtained for naming speed and short-term memory in turn.

In Experiments 2 and 3, we found that age of acquisition had reliable effects on naming speed while frequency did not. Other researchers have shown that naming latency correlates more strongly with age of acquisition than with word frequency (e.g., Rubin, 1980), and some studies appear to show no independent effect of frequency when age of acquisition is controlled (e.g., Brown \& Watson, 1987; Gilhooly \& Logie, 1981a, 1981b). The results reported here add weight to the argument that age of acquisition, rather than word frequency, affects word naming performance. Attempting to explain all the findings of frequency effects on word naming as an age of acquisition artifact is clearly a contentious issue, and we would not like to make strong claims in this respect from our own data. The major point of the naming data reported, for our present purposes, is that age of acquisition did have a significant effect on naming latency in both experiments, as others have shown.

Theoretically, it appears that age of acquisition has effects on mechanisms responsible for speech production (Brown \& Watson, 1987; Gilhooly \& Watson, 1981)possibly on the speed of access to phonological representations stored in a speech output lexicon, or on the speed with which those representations can be converted into speech motor codes and executed as articulations. Since in Experiment 1 we found that there was an effect of age of acquisition on simply repeating a single word and pairs of words, it seems that the effect may, at least in part, be on the speed of execution of speech motor programs. Given the close link between the rate at which words can be articulated and how well they are remembered (see, e.g., Baddeley \& Hitch, 1974; Schweickert $\&$ Boruff, 1986), this certainly provides a mechanism by 
which age of acquisition could affect memory span. However, the magnitude of this effect on speech rate observed in these experiments was simply too small to produce a reliable effect on memory span. Typically experiments that have studied the relationship between speech rate and short-term memory have manipulated the number of syllables in the words used (Baddeley et al., 1975; Hulme et al., 1991). This results in much larger differences in speech rate than those observed between the sets of words used in Experiment 1, which were matched for the number of phonemes they contained.

What then, do the present experiments tell us about the mechanisms underlying short-term memory span? They provide another demonstration, carried out according to a different methodology, that frequency has a direct effect on short-term memory processes that is not mediated by speech rate. Tehan and Humphreys (1988) and Gregg et al. (1989) have demonstrated that effects of word frequency on short-term memory span did not disappear under articulatory suppression, as would be expected if the effect of frequency were mediated entirely by speech rate. Roodenrys et al. (1994) have shown that separate functions relate speech rate to memory span for high- and low-frequency words, and that partialling out variability in memory span scores associated with variability in speech rate does not remove the frequency effect. In Experiment 1, we managed to equate high- and low-frequency words on age of acquisition and also on speech rate. These sets of words, however, showed a highly significant effect on memory span, and this provides a further demonstration that frequency has a direct effect on short-term memory processes that is independent of speech rate. In Experiment 3, we replicated this effect, although there was a small effect of frequency on speech rate in this experiment.

We believe that the effect of word frequency on shortterm memory processes that is not mediated by speech rate is due to a long-term memory contribution to shortterm memory tasks. We propose that when the partially decayed trace of a word is retrieved from the phonological short-term store, it is automatically subjected to some type of "clean-up" or pattern completion process. These clean-up processes, we believe, depend on longterm memory representations of the phonological form of words. We believe that the effect of frequency on short-term memory span is due to differences in the accessibility of these phonological representations in long-term memory. We construe this process to be very similar to the process of auditory word recognition, and this process could be captured well by the notion of automatic pattern completion in a connectionist network responsible for speech perception (see Brown, 1990, and Hulme et al., 1991, for further discussion of this idea).

In summary, our data show that frequency and age of acquisition have separable effects on language processing mechanisms. Frequency has a direct effect on shortterm memory span that is not mediated by speech rate. We believe that this effect reflects processes operating on the retrieval of information from a short-term phonological store that is subject to the loss of information by decay. In contrast, age of acquisition affects the rate at which words can be named and repeated. Although such effects on speech rate might be expected to affect shortterm memory span, the magnitude of these effects was too small to produce reliable effects on memory span.

\section{REFERENCES}

BADDELEy, A. D. (1986). Working memory. Oxford: Oxford University Press,

BADDEleY, A. D., \& Hirch, G. J. (1974). Working memory, In G. Bower (Ed.), Recent advances in learning and motivation (pp. 47-90). New York: Academic Press.

Baddeley, A. D., Lewis, V. J., \& Vallar, G. (1984). Exploring the articulatory loop. Quarterly Journal of Experimental Psychology, 36, 233-252

Baddeley, A. D., Thomson, N., \& Buchanan, M. (1975). Word length and the structure of short-term memory. Journal of Verbal Learning \& Verbal Behavior, 14, 575-589.

Brown, G. D. A. (1984). A frequency count of 190,000 words in the London-Lund Corpus of English conversation. Behavior Research Methods, Instruments, \& Computers, 16, 502-532.

Brown, G. D. A. (1990). Short-term memory capacity limitations on recurrent speech production and perception networks. In Proceedings of the Eleventh Annual Conference of the Cognitive Science Society (pp. 572-579). Hillsdale, NJ: Erlbaum.

Brown, G. D. A., \& WATson, F. L. (1987). First in, first out: Word learning age and spoken word frequency as predictors of word familiarity and word naming latency. Memory \& Cognition, 15, 208-216.

Clark, H. H. (1973). The language-as-fixed-effect fallacy: A critique of language statistics in psychological research. Journal of Verbal Learning \& Verbal Behavior, 12, 335-359.

Cox, R., Hulme, C., \& Brown, G. D. A. (1992). STM Experimenter: Using Hypercard and MacRecorder in short-term memory experiments. Behavior Research Methods, Instruments, \& Computers, 24, 575-579.

Geffen, G., \& Luszcz, M. A. (1983). Are the spoken durations of rare words longer than those of common words? Memory \& Cognition, 11, 13-15

Gilhooly, K. J., \& LoGIE, R. H. (1980). Age-of-acquisition, imagery, concreteness, familiarity, and ambiguity measures for 1,944 words. Behavior Research Methods \& Instrumentation, 12, 395-427.

Gilhooly, K. J., \& LoGIE, R. H. (1981a). Word age-of-acquisition, reading latencies and auditory recognition. Current Psychological Research, 1, 251-262.

Gilhooly, K. J., \& LOGIE, R. H. (1981b). Word age-of-acquisition and visual recognition thresholds. Current Psychological Research, 1, 215-226.

Gilhooly, K. J., \& WaTSON, F. L. (1981). Word age-of-acquisition effects: A review. Current Psychological Research, 1, 269-286.

Gregg, V. H., Freedman, C. M., \& Smith, D. K. (1989). Word frequency, articulatory suppression and memory span. British Journal of Psychology, 80, 363-374.

Hulme, C., Maughan, S., \& Brown, G. D. A. (1991). Memory for familiar and unfamiliar words: Evidence for a long-term memory contribution to short-term memory span. Journal of Memory \& Language, 30, 685-701.

Lachmann, R., Shaffer, J. P., \& Hennrikus, D. (1974). Language and cognition: Effects of stimulus codability, name-word frequency, and age of acquisition on lexical RT. Journal of Verbal Learning \& Verbal Behavior, 13, 613-625.

Morrison, C. M., Ellis, A. W., \& Quinlan, P. T. (1992). Age of acquisition, not word frequency, affects object naming, not object recognition. Memory \& Cognition, 20, 705-714.

Murray, D. J. (1968). Articulation and acoustic confusability in short-term memory. Journal of Experimental Psychology, 78, 679684 
PenNey, C. G. (1989). Modality effects and the structure of short-term verbal memory. Memory \& Cognition, 17, 398-422.

QuinLan, P. T. (1992). The Oxford psycholinguistic database. Oxford: Oxford University Press.

Roodenrys, S., Hulme, C., Schweickert, R., \& Brown, G. D. A. (1994). Word frequency effects on short-term memory span: Further evidence for a long-term memory contribution to short-term memory span. Manuscript in preparation.

RuBIN, D. C. (1980). 51 properties of 125 words: A unit analysis of verbal behavior. Journal of Verbal Learning \& Verbal Behavior, 19, 736-755. SCHWEICKERT, R., \& BoRUFF, B. (1986). Short-term memory capacity:
Magic number or magic spell? Journal of Experimental Psychology: Learning, Memory, \& Cognition, 12, 419-425.

Tehan, G., \& Humphreys, M. S. (1988). Articulatory loop explanations of memory span and pronunciation rate correspondences: A cautionary note. Bulletin of the Psychonomic Society, 26, 293296.

WatKINS, M. J. (1977). The intricacy of memory span. Memory \& Cognition, 5, 529-534.

WriGHT, C. E. (1979). Duration differences between rare and common words and their implications for the interpretation of word frequency effects. Memory \& Cognition, 7, 411-419.

\begin{tabular}{|c|c|c|c|c|c|c|c|c|}
\hline \multicolumn{9}{|c|}{$\begin{array}{l}\text { APPENDIX } \\
\text { Stimulus Sets }\end{array}$} \\
\hline & \multicolumn{4}{|c|}{ Frequency } & \multicolumn{4}{|c|}{ Age of Acquisition } \\
\hline & \multicolumn{2}{|c|}{ Low } & \multicolumn{2}{|c|}{ High } & \multicolumn{2}{|c|}{ Low } & \multicolumn{2}{|c|}{ High } \\
\hline & \multicolumn{2}{|c|}{$\begin{array}{l}\text { excuse } \\
\text { howl } \\
\text { win } \\
\text { tap } \\
\text { prayer } \\
\text { plug } \\
\text { aunt } \\
\text { smoke }\end{array}$} & \multicolumn{2}{|c|}{$\begin{array}{l}\text { Experiment } 1 \\
\text { moment } \\
\text { place } \\
\text { find } \\
\text { back } \\
\text { year } \\
\text { money } \\
\text { home } \\
\text { school }\end{array}$} & \multicolumn{2}{|c|}{$\begin{array}{l}\text { danger } \\
\text { soldier } \\
\text { upset } \\
\text { autumn } \\
\text { whisper } \\
\text { silence } \\
\text { learning } \\
\text { wonder }\end{array}$} & \multicolumn{2}{|c|}{$\begin{array}{l}\text { review } \\
\text { column } \\
\text { latter } \\
\text { token } \\
\text { discharge } \\
\text { budget } \\
\text { factor } \\
\text { extent }\end{array}$} \\
\hline & $M$ & $S D$ & $M$ & $S D$ & $M$ & $S D$ & $M$ & $S D$ \\
\hline Frequency & 3.75 & 2.9 & 131.75 & 54.0 & 4.63 & 6.35 & 4.63 & 6.35 \\
\hline \multicolumn{9}{|l|}{ Age of } \\
\hline Concreteness & 462.0 & 99.9 & 458.6 & 110.8 & 383.6 & 104.6 & 379.6 & 88.3 \\
\hline & \multicolumn{2}{|c|}{$\begin{array}{l}\text { nod } \\
\text { bite } \\
\text { lady } \\
\text { song } \\
\text { lap } \\
\text { coal } \\
\text { cousin } \\
\text { rubber } \\
\text { pit } \\
\text { hive } \\
\text { surprise } \\
\text { boast } \\
\text { border } \\
\text { pioneer }\end{array}$} & \multicolumn{2}{|c|}{$\begin{array}{l}\text { road } \\
\text { book } \\
\text { paper } \\
\text { room } \\
\text { half } \\
\text { line } \\
\text { people } \\
\text { coffee } \\
\text { case } \\
\text { part } \\
\text { country } \\
\text { reason } \\
\text { matter } \\
\text { degree }\end{array}$} & \multicolumn{2}{|c|}{$\begin{array}{l}\text { net } \\
\text { heat } \\
\text { date } \\
\text { flock } \\
\text { crush } \\
\text { plug } \\
\text { heaven } \\
\text { smile } \\
\text { spell } \\
\text { mermaid } \\
\text { stable } \\
\text { magic } \\
\text { rope } \\
\text { holiday }\end{array}$} & \multicolumn{2}{|c|}{$\begin{array}{l}\text { booth } \\
\text { nerve } \\
\text { tape } \\
\text { dusk } \\
\text { plot } \\
\text { flesh } \\
\text { fraud } \\
\text { rent } \\
\text { scheme } \\
\text { circuit } \\
\text { priest } \\
\text { moral } \\
\text { jade } \\
\text { committee }\end{array}$} \\
\hline & $M$ & $S D$ & $M$ & $S D$ & $M$ & $S D$ & $M$ & $S D$ \\
\hline Frequency & 2.64 & 2.7 & 89.8 & 129.9 & 4.21 & 5.39 & 4.29 & 5.18 \\
\hline $\begin{array}{l}\text { Age of } \\
\text { acquisition }\end{array}$ & 3.03 & 0.81 & 3.05 & 0.83 & 2.82 & 0.33 & 4.72 & 0.55 \\
\hline Concreteness & 496.7 & 95.3 & 490.4 & 97.2 & 466.7 & 104.3 & 460.7 & 114.7 \\
\hline
\end{tabular}

(Manuscript received May 19, 1993;

revision accepted for publication January $10,1994$. 